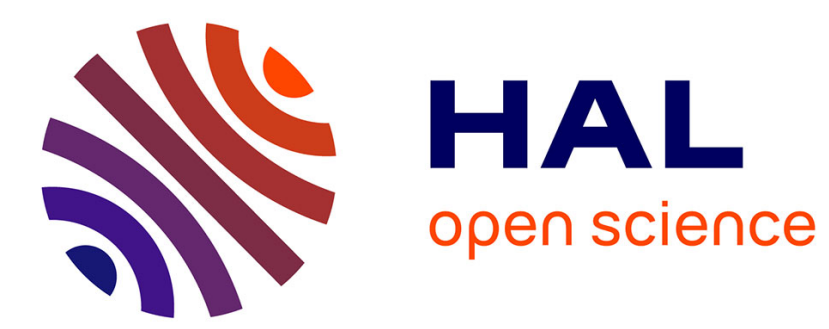

\title{
Taxation of a Digital Monopoly Platform
}

\author{
Marc Bourreau, Bernard Caillaud, Romain de Nijs
}

\section{To cite this version:}

Marc Bourreau, Bernard Caillaud, Romain de Nijs. Taxation of a Digital Monopoly Platform . 2016. hal-01387357

\section{HAL Id: hal-01387357 \\ https://hal-polytechnique.archives-ouvertes.fr/hal-01387357}

Preprint submitted on 25 Oct 2016

HAL is a multi-disciplinary open access archive for the deposit and dissemination of scientific research documents, whether they are published or not. The documents may come from teaching and research institutions in France or abroad, or from public or private research centers.
L'archive ouverte pluridisciplinaire HAL, est destinée au dépôt et à la diffusion de documents scientifiques de niveau recherche, publiés ou non, émanant des établissements d'enseignement et de recherche français ou étrangers, des laboratoires publics ou privés. 


\title{
ECOLE POLYTECHNIQUE
}

\section{Taxation of a Digital Monopoly Platform}

\author{
Marc BOURREAU \\ Bernard CAILLAUD \\ Romain DE NIJS
}

October 25, 2016

Cahier $n^{\circ}$ 2016-18

\section{DEPARTEMENT D'ECONOMIE}

Route de Saclay

91128 PALAISEAU CEDEX

(33) 169333033

http://www.portail.polytechnique.edu/economie/fr

mariame.seydi@polytechnique.edu 


\title{
Taxation of a Digital Monopoly Platform*
}

\author{
Marc Bourreau ${ }^{\dagger}$ Bernard Caillaud ${ }^{\ddagger}$ Romain De Nijs ${ }^{\S}$
}

October 25, 2016

\begin{abstract}
This paper investigates the impact on fiscal revenues of taxing a two-sided monopolistic platform offering personalized services to users and targeted advertising to sellers, based on the collection of users' personal data. We show that the introduction of a small tax on data collection, which has been proposed in the French context by Colin and Collin (2013), fails to increase fiscal revenues if the value added tax (VAT) rate is high enough, due to a tax base interdependence effect between the two taxes. Under a supermodularity condition on the platform's profit function as a function of its prices, this result generalizes to any per-unit tax. However, in some cases, an ad valorem tax on subscriptions or on advertising may raise fiscal revenues, irrespective of the VAT rate, as well as welfare.
\end{abstract}

Keywords: two-sided market, digital economy, online advertising, data, taxation. JEL Classification: H2, L1, L2.

\section{Introduction}

Besides its role as a source of technical and organizational change and as one of the main engines of growth, what is known as the Digital Economy has also become a source of major concern for governments, in particular fiscal authorities. The major companies in the Digital Economy are as of today the most profitable firms in the global economy. In 2015 , Google earned $\$ 74.5$ billion in revenue and $\$ 23.4$ billion of operating income. ${ }^{1}$ Facebook's stock value has more than doubled since its initial public offering in 2012,

* This research has been financed by France Strategie, within the general framework of a Research Project on the "Evolution of the Value created by the Digital Economy and its Fiscal Consequences", signed between France Strategie and a consortium consisting of PSE, Telecom ParisTech and TSE. We have benefited from the hospitality of CREST and from comments and discussion with M. Bacache, P.J. Benghozi, F. Bloch, J. Cremer, G. Demange, S. Gauthier, L. Gille, J. Hamelin, L. Janin, J.M. Lozachmeur, F. Manenti and B. Salanié.

†Telecom ParisTech; Email: marc. bourreau@telecom-paristech.fr.

${ }^{\ddagger}$ Paris School of Economics - Ecole des Ponts ParisTech; Email: caillaud@pse.ens.fr.

$\S$ Department of Economics, Ecole Polytechnique; E-mail: romain.de-nijs@polytechnique.edu.

${ }^{1}$ See http://www.engadget.com/2016/02/01/google-alphabet-q4-2015-earnings/. 
reaching about $\$ 300$ billion at the end of $2015 .^{2}$ Yet, these giant companies are wellknown for their low effective rate of taxation and for their ability to design worldwide fiscal strategies to take advantage of fiscal competition internationally.

Following the financial crisis, governments faced with severe budget constraints have launched several initiatives to be able to capture a larger part of the digital value creation. ${ }^{3}$ In 2014, the OECD published a report on the Base Erosion and Profit Shifting Project, whose aim was to prevent the transfer of profits to low corporate tax entities. ${ }^{4}$ The European Commission has also recently launched an Anti Tax Avoidance Package "for fairer, simpler and more effective corporate taxation in the EU." ${ }^{5}$ Finally, in 2013, a French expert mission on the taxation of the digital economy, known as the Colin and Collin report (2013), has drawn a tax project on data tracking.

As the OECD (2014) report outlines, "the digital economy and its business models present some key features which are potentially relevant from a tax perspective. These features include mobility, reliance on data, network effects, the spread of multi-sided business models, a tendency toward monopoly or oligopoly and volatility." Our paper proposes a model of the digital economy that takes explicitly into account several of these features: platforms have two-sided business models, they rely critically on data collection and they have market power. This model is then used to assess the impact of various taxes that have been proposed so as to target implicitly dominant digital platforms; in particular, we will evaluate the possibility of a tax on data collection in the spirit of Colin and Collin $(2013)$.

The idea of Colin and Collin (2013) is that personal data are a form of "free work" for online platforms that should be taxed not only to raise additional fiscal revenues but also to put on a more equal footing online and offline industries. Colin and Collin (2013) see the tax on personal data as a second best solution that can be implemented on a national level pending a more comprehensive reform of the taxation of the digital economy at a European or even a world level. Our model is in line with this view because it does not consider tax competition between different countries and assumes that the platform

\footnotetext{
${ }^{2}$ See https://ycharts.com/companies/FB/market_cap.

${ }^{3}$ See, among others, the reports written for the French Conseil National du Numérique (2013), for the EC (Gaspar et al., 2014), and for HM Treasury (2014).

${ }^{4}$ See OECD (2014).

${ }^{5}$ See "Fair Taxation: Commission presents new measures against corporate tax avoidance," European Commission, 28 January 2016, http://europa.eu/rapid/press-release_IP-16-159_en.htm.
} 
cannot be taxed on the basis of its profits but only through the amount of data collected in a given country and the amount of transactions realized in this country.

More precisely, we develop a model in which a dominant (monopolistic) digital platform relies on users' personal data to provide personalized services to users and sell targeted advertising slots to online sellers. Web-users derive potential benefits from being targeted with relevant advertising on top of having personalized services. Online sellers benefit from the large audience of the platform, particularly when this platform relies on personal data, collected on each user, that help it provide a better targeting technology and therefore more efficient advertising campaigns for sellers. These features characterize a standard two-sided business model ${ }^{6}$ with a novelty regarding the role of data that are an essential input for the platform.

Many observers suggest that this type of business model implies that most of the value created by a digital platform comes from the data input that is provided by users, an input that is free for the platform. This view has led Colin and Collin (2013) to propose specific taxes on data collection and usage. Indeed, a small tax on data collection borne by the platform has no direct impact on the "price of data", which is equal to zero; the fiscal base is insensitive to the tax rate and a tax on data would seem to be adequate to capture part of the platform's profits. However, taking into account the two-sided nature of platforms changes the picture radically. We show how a tax on data collection impacts the market for advertising and ultimately reduces the volume of transactions generated by targeted advertising. As a result, a tax base interdependence effect kicks in between a tax on data and VAT. Moreover, platforms who charge users for their base services may also respond to a tax on data by charging users subscription fees.

Since advertising is the main source of revenue of major digital platforms, it may also be legitimate to consider a tax on online advertising revenues, a possibility that has been much fought against by professionals in advertising. An ad valorem tax on advertising seems to be superior to a tax on data since it is actually neutral in a model where the platform is free for users and does not bear significant variable costs. But if the platform follows a more balanced business model, charging a subscription fee on users and a price on advertising, the same tax base interdependence effect arises for all types of taxes whenever

\footnotetext{
${ }^{6}$ General references on two-sided markets include Caillaud and Jullien (2003), Rochet and Tirole (2003) and Armstrong (2006). Papers more specifically focused on advertising-based business models include Anderson and Coate (2005) and Peitz and Valletti (2008).
} 
the platform responds to the tax by increasing prices on both sides of its activities. The critical point, however, is that even if the platform's objective function is well behaved, i.e., supermodular with respect to its prices, it may react to the introduction of an $a d$ valorem tax on advertising by decreasing either the advertising price, or subscription fees, or even both. In such a case, the tax base interdependence effect vanishes and ad valorem taxes dominate per unit taxes with respect to fiscal revenues.

Our paper contributes to clarify the effects of various forms of taxation in a two-sided economy. Since the seminal works of Suits and Musgrave (1953) and Delipalla and Keen (1992), a consensus that ad valorem taxes welfare dominate equal-yield unit taxes for a wide range of imperfect competitive settings has been obtained (See Keen (1998) for a survey). Kind et al. (2008), (2010a) and (2010b) are the first articles that analyze taxation in a two-sided setting. They show that ad valorem taxes do not necessarily dominate unit taxes as they do in a standard environment in terms of tax revenues or welfare. By contrast, our model suggests that ad valorem taxes may dominate other taxes in terms of tax revenues because they can mitigate the tax base interdependence effect with the VAT. Second, Kind et al. show most interestingly that the price of a good may decrease with the ad valorem tax rate, which is precisely why ad valorem taxes may avoid the tax base interdependence effect with the VAT in our model. To our knowledge, there exists no formal analysis of a tax on data collection but in Bloch and Demange (2016), who investigate in a different setting than ours the effects of different tax instruments on the level of data collection by a digital platform.

The model is presented in Section 2 in some details as it is of independent interest and tractable. In Section 3, we analyze the case of a platform whose access is provided for free to users while in Section 4, we study the more general case in which the platform also charges users a subscription fee. Section 5 proposes an example that illustrates some of our findings.

\section{A model of platform relying on personal data}

A monopolistic Internet platform, say a dominant content provider, collects personal data on heterogeneous users to provide valuable personalized services to these users and offer the possibility of targeted advertising to a heterogeneous population of sellers. Users care 
about the amount and the relevance of the ads they receive, and advertisers care about the platform's audience: i.e., this is a two-sided platform. In this economy, all economic activities are subject to a value-added tax (VAT). We will study the introduction of other fiscal instruments: an infinitesimally small tax on data collection, in the spirit of Colin and Collin (2013), as well as more standard (infinitesimally small) per unit or ad valorem taxes on users' subscription to the platform or on advertising.

Users. Let $x \in[0, X] \subset \mathbb{R}_{+}$denote the quantity of personal data that a user (she) decides to disclose to the platform. This quantity is perfectly controlled by the user: it can correspond to the personal information she willingly provides or uploads on the platform, the authorization she gives for her geo-location to be known or for cookies to be used by the platform, the comments and ratings she writes, and more generally her past browsing history on the platform.

The platform offers the consumer a personalized service of value $v(x)$, where $v($.$) is$ increasing concave and $v(0) \geq 0$ (See Arora et al. (2008)). Moreover, data help the platform perform targeted advertising: we summarize the quality of this service by $\lambda(x)$, the probability per active seller that the user under scrutiny is reached by a relevant ad from this seller, ${ }^{7}$ with $\lambda($.$) increasing concave and \lambda(0) \geq 0$. By "relevant ad", we mean an ad that induces the user to click, and that can potentially generate a transaction between the seller and the user. We let $\sigma$ denote the user's expected net surplus of transaction associated with a relevant ad. Users are indexed by $\theta$, their marginal disutility of increasing the amount of personal data they let the platform collect, which we will call the marginal utility of privacy. We assume that $\theta$ is distributed according to the c.d.f. $F($.$) , with density f($.$) , on [0,1]$.

Online sellers. Online sellers benefit from a relevant match as they can make a transaction with the users who click on their ad. Online sellers pay the platform on a pay-per-click basis, assuming for simplicity that all relevant matches translate into a click, at a unit net price equal to $a$, with $a \geq 0 .{ }^{8}$ They are characterized by a cost parameter

\footnotetext{
${ }^{7}$ Anecdotal evidence suggests that consumers internalize the possibility of better targeted ads when they decide how much information to share with a platform. According to Joseph Turow, a professor at Penn's Annenberg School for Communication "Companies are saying that people give up their data because they understand they are getting something for those data". According to Mike Zaneis, the chief counsel for the Interactive Advertising Bureau: "People are always willing to trade privacy and information when they see the direct value of sharing that information" (the citations are from Singer, 2015).

${ }^{8}$ The ad price is non-negative to prevent sellers from generating revenues by fake clicks.
} 
$c$ that determines $\pi(c)=r(c)-\gamma(c)$, the seller's profit in a transaction, equal to the difference between the seller's revenue and the seller's cost, and $s(c)>0$, the user's net surplus from the transaction. We assume that $\pi(c)$ is decreasing in $c$ and $\pi(0)>0 .{ }^{9}$ Finally, we assume that the cost parameter $c$ is distributed according to the c.d.f. $G($.$) ,$ with density $g($.$) , on \mathbb{R}_{+}$.

Letting $t$ denote the VAT rate, the expected profit of each seller per relevant ad generated is given by $(\pi(c)-a) /(1+t)$, since advertisers are able to reclaim the VAT proceeds on their intermediate consumption (advertising and production costs). It follows that the set of participating sellers on the platform is given by $[0, \bar{c}(a)]$ such that: $\pi(\bar{c}(a))=a$, so that $\bar{c}($.$) is positive decreasing provided that a<\pi(0)$.

Users' participation. We can now turn to users' participation to the platform. Users' expected surplus of transaction is given by:

$$
\sigma(a)=\int_{0}^{\bar{c}(a)} s(c) d G(c),
$$

a decreasing function of $a$ for $a<\pi(0)$. When she participates in the platform, a user of type $\theta$ chooses the quantity of data to be collected such that:

$$
x(\theta ; a) \equiv \arg \max _{0 \leq x \leq X}\{v(x)-\theta x+\lambda(x) \sigma(a)-A\},
$$

assuming that the platform charges the user a subscription fee $A \geq 0 .{ }^{10}$ Our assumptions imply that $x(\theta ; a)$ is unique, decreasing in both its arguments when it is interior, and that $x(0 ; a)>0$. The maximized utility is a decreasing function of $\theta$ by the envelope theorem so that we let $\bar{\theta}(A, a)$ denote the maximal element of the set of participating users $[0, \bar{\theta}(A, a)]$, for which the utility of participation is non-negative; whenever interior, $\bar{\theta}(A, a)$ is a decreasing function of both its arguments.

Platform. Let $X(A, a) \equiv \int_{0}^{\bar{\theta}(A, a)} x(\theta ; a) d F(\theta)$ denote the aggregate amount of data

\footnotetext{
${ }^{9} \mathrm{~A}$ possible foundation for this model is the following. Users derive utility $u(q)-p q$ when they buy $q$ units at price $p$ in the transaction; their individual demand function is then $d(p)=\left(u^{\prime}\right)^{-1}(p)$. A seller will face such a demand whenever it is matched with a user and will charge a monopoly price $p^{M}(c)=$ $\arg \max _{p}(p-c) d(p)$. Then, we have $r(c)=p^{M}(c) d\left(p^{M}(c)\right), \gamma(c)=c d\left(p^{M}(c)\right), \pi(c)=\max _{p}(p-c) d(p)$ decreasing in $c$ (envelope theorem), and $s(c)=u\left(d\left(p^{M}(c)\right)\right)-p^{M}(c) d\left(p^{M}(c)\right)$.

${ }^{10} \mathrm{We}$ will normalize subscription charges to be non-negative. In principle, they could be negative to the extent that the platform could provide users with a free additional service. In this model, however, negative subscription fees do not increase the flow of data compared to a null subscription fee. Hence, we discard this possibility.
} 
collected by the platform, and $\Lambda(A, a) \equiv \int_{0}^{\bar{\theta}(A, a)} \lambda(x(\theta ; a)) d F(\theta)$ the total amount of relevant ads and of valuable clicks per participating seller. Note that $G(\bar{c}(a)) \Lambda(A, a)$ represents the total amount of ad-generated transactions in the economy. Given the previous assumptions, $X(A, a), \Lambda(A, a), G(\bar{c}(a)) \Lambda(A, a)$ and $F(\bar{\theta}(A, a))$ are all decreasing functions of both price instruments provided that $0<a<\pi(0)$ and $0<\bar{\theta}(A, a)<1$.

Letting $\gamma(X, G(\bar{c}), G(\bar{c}) \Lambda)$ (omitting the price arguments) denote the operating costs of the platform, assumed to be increasing in the amount of data collected, the number of ads and the number of relevant ads, the platform's profits are given by:

$\Pi^{P}(A, a ; \phi)=\frac{1}{1+t} \int_{0}^{\bar{\theta}(A, a)}[A+a G(\bar{c}(a)) \lambda(x(\theta ; a))] d F(\theta)-\Gamma(A, a)-\phi \int_{0}^{\bar{\theta}(A, a)} x(\theta ; a) d F(\theta)$,

where $\phi$ is the small tax rate on the amount of collected data, that we assume is paid by the platform, and $\Gamma(A, a) \equiv \gamma(X(A, a), G(\bar{c}(a)), G(\bar{c}(a)) \Lambda(A, a))$. It will be convenient to use $\psi=(1+t) \phi$ and

$$
\Pi^{0}(A, a) \equiv A F(\bar{\theta}(a, A))+a G(\bar{c}(a)) \Lambda(A, a)-(1+t) \Gamma(A, a)
$$

so that the platform's profit, normalized by $(1+t)$, can be written as: $(1+t) \Pi^{P}(A, a ; \psi)=$ $\Pi^{0}(A, a)-\psi X(A, a)$.

When considering other forms of taxation paid by the platform, its normalized profits are easily obtained as the difference between $\Pi^{0}(A, a)$ and the additional fiscal burden equal respectively to $\alpha(1+t) F(\bar{\theta}(A, a))$ for a per unit tax on subscriptions, $\tau A F(\bar{\theta}(A, a))$ for an ad valorem tax on subscriptions, $\zeta(1+t) G(\bar{c}(a)) \Lambda(A, a)$ for a per unit tax on advertising and $\beta a G(\bar{c}(a)) \Lambda(A, a)$ for an ad valorem tax on advertising.

Fiscal revenues. In order to assess the performance of fiscal instruments, we characterize the total tax proceeds that accrue to the fiscal authority, which are given by:

$$
\begin{aligned}
T & =\frac{t}{1+t} \int_{0}^{\bar{\theta}(A, a)}[A+R(a) \lambda(x(\theta ; a))] d F(\theta)+\phi \int_{0}^{\bar{\theta}(A, a)} x(\theta ; a) d F(\theta) \\
& \equiv \frac{1}{1+t}\left[t B^{0}(A, a)+\psi X(A, a)\right]
\end{aligned}
$$

where we let $R(a) \equiv \int_{0}^{\bar{c}(a)} r(c) d G(c)$ denote the total revenue of sellers generated through online advertising, which is a decreasing function of $a$ provided that $a<\pi(0)$, and 
$B^{0}(A, a) \equiv A F(\bar{\theta}(A, a))+R(a) \Lambda(A, a)$ denote the users' total spending on subscriptions and purchase of goods.

For other forms of taxation, fiscal revenues are equal to the sum of the VAT proceeds and of the additional platform's fiscal burden written explicitly above in the different cases (divided by $1+t$ ).

Welfare. Finally, we define social welfare $(W)$ as the sum of consumer surplus $(C S)$, sellers' profits $(S P)$ and fiscal revenues $(T)$. We do not include the platform's profits into social welfare, assuming it is a foreign platform.

Consumer surplus is given by

$$
C S(A, a)=\int_{0}^{\bar{\theta}(A, a)}[v(x(\theta ; a))+\lambda(x(\theta ; a)) \sigma(a)-\theta x(\theta ; a)-A] d F(\theta)
$$

and sellers' profits are

$$
S P(A, a)=\Lambda(A, a) \int_{0}^{\bar{c}(a)}\left(\frac{\pi(c)-a}{1+t}\right) d G(c)
$$

From our previous assumptions, $C S$ and $S P$ are decreasing functions of $A$ and $a$.

\section{A free-for-users platform}

Major content-providing platforms such as Google or Yahoo are purely financed by advertising and their access is free for web-browsers. We start our analysis by taking the form of this business model as given and assume that $A=0$; that is, the platform only generates revenues by charging sellers for their online advertisements.

Note first that given that all users may simply choose not to upload any data, we can consider w.l.o.g. that all of them participate, i.e., $\bar{\theta}(0, a)=1$. If it is active, the platform chooses the price of advertising so as to maximize its expected profits net of taxes:

$$
a^{*}(\psi)=\arg \max _{0 \leq a \leq \pi(0)}\left\{\Pi^{0}(0, a)-\psi X(0, a)\right\}
$$

For small enough tax rates, our assumptions guarantee that if there exists a level of the advertising price that is profitable for the platform, it is interior. ${ }^{11}$ Assuming a unique

\footnotetext{
${ }^{11}$ The objective function for $\psi=0$ is non-positive for $a=0$ and for $a \geq \pi(0)$.
} 
profitable solution, Topkis' theorem guarantees that $a^{*}(\psi)$ is an increasing function of the tax rate on data collection, for $\psi$ in a neighborhood of 0 . Our first proposition characterizes the effectiveness of a tax on data collection to generate additional fiscal revenues.

Proposition 1 : In the case of a free-for-users platform, if $\Pi^{0}(0, a)$ has a unique positiveprofit maximum in a, there exists a critical threshold $\bar{t}$ for the VAT rate such that the introduction of a small tax on data collection generates additional fiscal revenues if and only if $t<\bar{t}$.

Proof. Computing the effect of an increase in $\psi$ on the fiscal revenues, evaluated at $\psi=0$, we obtain:

$$
\left.(1+t) \frac{d T}{d \psi}\right|_{\psi=0}=X\left(0, a^{*}(0)\right)+t \cdot \frac{\partial a^{*}}{\partial \psi}(0) \cdot \frac{d}{d a}\left[B^{0}(0, a)\right]_{a^{*}(0)} .
$$

Given that $R(a)$ and $\Lambda(0, a)$ are both positive decreasing in $a, \frac{d}{d a}\left[B^{0}(0, a)\right]_{a^{*}(0)}<0$ and the result follows since $a^{*}(\psi)$ increases in $\psi$, with

$$
\bar{t} \equiv X\left(0, a^{*}(0)\right)\left[-\frac{\partial a^{*}}{\partial \psi}(0) \cdot \frac{d}{d a}\left[B^{0}(0, a)\right]_{a^{*}(0)}\right]^{-1}
$$

This result shows that a tax on data collection competes with the VAT, which limits the effectiveness of the introduction of this per unit tax to raise fiscal revenues. When the VAT rate is high, this tax base interdependence effect dominates the direct effect on fiscal revenues. The main point is that the tax base interdependence does not come from substitution effects within consumers' behavior as is usual in the literature on taxation, but rather from the platform's modified behavior due to its two-sided nature.

Suppose, as a benchmark, that $\sigma$ were perceived by users as independent of $a$, i.e., suppose users do not care about the sellers' behavior. Then, users' decisions of participation and of data uploading would be independent of $a$ as well. It follows that, faced with a tax on data collection, the platform would have no means to reduce its tax burden by inducing users to limit their data uploading. In other words, a tax on data collection would not induce any real change in the economy, neither on the volume of data collected, nor on the volume of advertising or on the volume of transactions. A tax on data 
collection, an inelastic and isolated activity, would then be a good idea.

However, users care about the sellers' behavior on the platform and sellers' behavior is affected by the price of advertising. So, in response to a tax on data collection, the platform can now dissuade users from uploading too many data by increasing the price on advertising, i.e., on the other side of the market. The mechanics is simple: an increase in the price of advertising reduces the number of advertising sellers, hence it reduces the value of uploading data on the platform for users, thereby reducing the volume of data collected, and the number of ad-generated transactions, thereby reducing the VAT proceeds. Therefore, users' participation is now elastic, although in an indirect way, with respect to the tax rate on data collection because of the cross-externality between users and sellers through the platform.

Are there easier ways to raise additional fiscal revenues? First, data not being monetized, there is no other tax base related to data collection that could be used. A per unit tax on advertising leads to a similar analysis as the per unit tax on data collection: it induces the platform to charge a price for ads that increases with the relevant tax rate and the local effect of the introduction of either taxes exhibits a positive direct effect and the same tax base interdependence effect as in (3) with $\left.\frac{\partial a^{*}}{\partial \alpha}\right|_{\alpha=0}$ instead. A large VAT rate makes the introduction of this tax counter-productive in terms of fiscal revenues. When the platform is purely financed by advertising revenues, the last possibility is an ad valorem tax on advertising, which induces the platform to maximize a normalized profit equal to $(1-\beta) a G(\bar{c}(a)) \Lambda(0, a)-(1+t) \Gamma(0, a)$. When costs are negligible or mostly fixed, an ad valorem tax on advertising is then neutral: it does not affect advertising prices, nor the amount of transactions in the economy, and it generates additional fiscal revenues without tax base interdependence effects. With non-degenerate marginal costs, however, the impact of the introduction of a small ad valorem tax on advertising is similar to the impact of the introduction of a small tax on data collection.

Welfare. Since $a^{*}(\psi)$ is an increasing function of $\psi$, and $C S$ and $S P$ decrease with the advertising price, consumer surplus and sellers' profits are both reduced when a small tax on data collection is introduced. If $t>\bar{t}$, fiscal revenues also decrease with $\psi$ (Proposition 1), and therefore social welfare unambiguously decreases with $\psi$. If $t \leq \bar{t}$, however, fiscal revenues increase with $\psi$. In this case, the introduction of a small tax on data collection involves a trade-off between larger fiscal revenues and lower consumer 
surplus and sellers' profits.

We've seen that an ad valorem tax on advertising does not affect the advertising price if costs are negligible. In this case, consumer surplus and sellers' profit are not affected by this type of tax either. Since fiscal revenues increase with an ad valorem tax on advertising, social welfare then also unambiguously increases.

\section{Two-sided financing of the platform}

Although many major players online have adopted an advertising-financed business model, this is by no means the general rule. Platforms such as Netflix extract revenues from users, and platforms such as Spotify extract revenues from both advertisers and users. Therefore, the choice of a business model should be viewed as endogenous, and depending on the business line and the type of services provided, a platform may find it optimal to charge users a subscription fee or to refrain from charging them such a fee. This has been discussed in the literature on two-sided platforms and we have not much to add to it. What we want to illustrate, however, is that both business models exhibit different responses to the introduction of various taxes. So, in this section, we will assume that the platform charges users a subscription fee $A$ on top of charging sellers for advertising.

If it is active, the platform now chooses its prices $\left(A^{*}(\psi), a^{*}(\psi)\right)$ in order to maximize its normalized expected profits $(1+t) \Pi^{P}(A, a ; \psi)=\Pi^{0}(A, a)-\psi X(A, a)$, where $\Pi^{0}(A, a)$ is given by (1). Assuming that this optimum is unique and interior for a small value of the tax rate, Proposition 1 then generalizes as follows:

Proposition 2 : In the general case of two-sided financing, if $\Pi^{0}(A, a)$ has a unique, positive-profit maximum $\left(A_{0}^{*}, a_{0}^{*}\right)$, such that $0<a_{0}^{*}<\pi(0)$ and $0<\bar{\theta}\left(A_{0}^{*}, a_{0}^{*}\right)<1$ and the platform's optimal subscription fee and advertising price are increasing (at least one of them strictly) in the tax rate $\psi$ around $\psi=0$, there exists a critical threshold $\bar{t}_{\psi}$ for the VAT rate such that the introduction of a small tax on data collection generates additional fiscal revenues if and only if $t<\bar{t}_{\psi}$.

Proof. Computing the local change in fiscal revenues from the introduction of a small 
tax on data collection, we obtain:

$$
\begin{aligned}
\left.(1+t) \frac{d T}{d \psi}\right|_{\psi=0} & =X\left(A_{0}^{*}, a_{0}^{*}\right)+t \cdot \frac{d a^{*}}{d \psi}(0) \cdot \frac{\partial}{\partial a}\left[B^{0}(A, a)\right]_{A_{0}^{*}, a_{0}^{*}} \\
& +t \cdot \frac{d A^{*}}{d \psi}(0) \cdot \frac{\partial}{\partial A}\left[B^{0}(A, a)\right]_{A_{0}^{*}, a_{0}^{*}} .
\end{aligned}
$$

Given our assumptions, $B^{0}(A, a)$ decreases in $a$ so that $\frac{\partial}{\partial a}\left[B^{0}(A, a)\right]_{A_{0}^{*}, a_{0}^{*}}<0$. Moreover, the FOC for profit maximization by the platform at $\psi=0$ implies:

$$
\left.\frac{\partial}{\partial A}[A F(\bar{\theta}(A, a))]\right|_{A_{0}^{*}, a_{0}^{*}}=-\left.a_{0}^{*} G\left(\bar{c}\left(a_{0}^{*}\right)\right) \frac{\partial \Lambda}{\partial A}(A, a)\right|_{A_{0}^{*}, a_{0}^{*}}+\left.(1+t) \frac{\partial \Gamma}{\partial A}(A, a)\right|_{A_{0}^{*}, a_{0}^{*}} .
$$

So,

$$
\frac{\partial}{\partial A}\left[B^{0}(A, a)\right]_{A_{0}^{*}, a_{0}^{*}}=\left.\left[R\left(a_{0}^{*}\right)-a_{0}^{*} G\left(\bar{c}\left(a_{0}^{*}\right)\right)\right] \frac{\partial \Lambda}{\partial A}(A, a)\right|_{A_{0}^{*}, a_{0}^{*}}+\left.(1+t) \frac{\partial \Gamma}{\partial A}(A, a)\right|_{A_{0}^{*}, a_{0}^{*}} .
$$

In this expression, the second term is negative since the cost $\gamma(X, G(\bar{c}), G(\bar{c}) \Lambda)$ increases in its arguments and $X(A, a)$ and $\Lambda(A, a)$ decrease in $A$. The sign of the first term depends on:

$$
R\left(a_{0}^{*}\right)-a_{0}^{*} G\left(\bar{c}\left(a_{0}^{*}\right)\right)=\int_{0}^{\bar{c}\left(a_{0}^{*}\right)}\left[r(c)-a_{0}^{*}\right] d G(c) .
$$

For participating sellers, it has to be that $r(c)$ is larger than the price-per-click, so that the term (5) above is positive. As $\Lambda(A, a)$ decreases in $A$, it follows that overall:

$$
\frac{\partial}{\partial A}\left[B^{0}(A, a)\right]_{A_{0}^{*}, a_{0}^{*}}<0
$$

The intuition is very similar to that of Proposition 1. In response to an increase in the tax on data collection, the platform reduces data uploading by increasing both its prices. The increase in the subscription fee reduces users' participation and data uploading; the increase in the price of advertising reduces sellers' participation and the users' benefits from targeted advertising. On the one hand, the revenue from subscriptions, as well as the VAT proceeds on subscriptions, increases. On the other hand, the reduction in data uploading and in sellers' participation induces a decrease in the volume of ad-generated transactions and consequently a reduction in VAT proceeds. Overall, the second effect dominates and total VAT proceeds decline: there is a tax base interdependence effect 
between the VAT and the tax on data collection. When the VAT rate is high enough, this tax base interdependence effect annihilates the direct tax revenue effect from the introduction of a small tax on data collection.

In terms of social welfare, we obtain similar results as in the previous section. Since consumer surplus and sellers' profits are decreasing in the platforms' prices and these prices increase with $\psi$, the introduction of a small tax on data collection hurts consumers and sellers. If $t>\bar{t}_{\psi}$, fiscal revenues also decrease and social welfare is unambiguously reduced. If $t \leq \bar{t}_{\psi}$, the tax on data collection involves a trade-off between larger fiscal revenues and lower surplus for consumers and sellers.

A sufficient condition for both subscription fees and advertising price to increase with $\psi$ is easily obtained:

Claim 3 : If $\Pi^{0}(A, a)$ has a unique, positive-profit, interior maximum $\left(A_{0}^{*}, a_{0}^{*}\right)$ and is strictly supermodular in $(A, a)$ in a neighborhood of $\left(A_{0}^{*}, a_{0}^{*}\right)$, the platform's optimal prices $\left(A^{*}(\psi), a^{*}(\psi)\right)$ are increasing in the tax rate around $\psi=0$.

The proof is an immediate application of Topkis' theorem given that $\Pi^{P}(A, a ; \psi)$ has strictly increasing differences in prices $(A, a)$ and $\psi$. This claim and Proposition 2 generalize easily to the introduction of any other small per unit tax on subscriptions or on advertising. ${ }^{12}$

However, in a full two-sided model, the platform's price response may not be monotonically increasing in an ad valorem tax rate, even assuming that $\Pi^{0}(A, a)$ exhibits strict supermodularity in $(A, a) \cdot{ }^{13}$ In the case of a free-for-users platform, an ad valorem tax is neutral as seen previously when costs are negligible, and in the full two-sided platform model, an ad valorem tax may actually induce a price decline for the following reason:

Claim 4 : Assume the costs of the platform are fixed; for an ad valorem tax on advertising, the platform's profit function has decreasing differences in a and $\beta$ (but increasing differences in $A$ and $\beta$ ) around the optimum; for an ad valorem tax on subscriptions, the platform's profit function has decreasing differences in $A$ and $\tau$ (but increasing differences in $a$ and $\tau$ ) around the optimum.

\footnotetext{
${ }^{12}$ For a per unit tax on advertising, the platform's additional tax burden is equal to $\alpha F(\bar{\theta}(A, a))$ and for the per unit tax on subscriptions, it is equal to $\zeta G(\bar{c}(a)) \Lambda(A, a)$; in both cases, the cross derivative with respect to one of the prices and the tax rate is negative, so that $\Pi^{P}$ has strictly increasing differences in any of the prices and the tax rate.

${ }^{13}$ As already noted by Kind et al. (2010a) and (2010b).
} 
Proof. For an ad valorem tax on advertising, we have

$$
(1+t) \Pi^{P}(A, a ; \beta)=A F(\bar{\theta}(A, a))+(1-\beta) a G(\bar{c}(a)) \Lambda(A, a) .
$$

At the optimum, the FOC yields at $\left(A^{*}(\beta), a^{*}(\beta)\right)$ :

$$
(1-\beta) \frac{\partial}{\partial a}[a G(\bar{c}(a)) \Lambda(A, a)]_{A^{*}(\beta), a^{*}(\beta)}=-\left.A^{*}(\beta) f\left(\bar{\theta}\left(A^{*}(\beta), a^{*}(\beta)\right)\right) \frac{\partial \bar{\theta}}{\partial a}\right|_{A^{*}(\beta), a^{*}(\beta)}>0
$$

It follows that:

$$
(1+t) \frac{\partial^{2}}{\partial \beta \partial a}\left[\Pi^{P}(A, a ; \beta)\right]_{A^{*}(\beta), a^{*}(\beta)}=-\frac{\partial}{\partial a}[a G(\bar{c}(a)) \Lambda(A, a)]_{A^{*}(\beta), a^{*}(\beta)}<0 .
$$

A similar proof holds for the case of a tax on subscriptions.

With an ad valorem tax on advertising or on subscriptions, it may therefore be the case that one price decreases with the corresponding tax rate. When the price decrease is strong enough or even when both prices decrease, these forms of taxation do not give rise to a tax base interdependence effect and so, they may generate additional fiscal revenues even for large values of the VAT rate: with respect to public finance, they may therefore be preferable to a tax on data collection. ${ }^{14}$ Below, we develop an example in which we can compute precisely and compare these effects.

The Claim shows that the platform's price response may not be monotonically increasing in the ad valorem tax rate whenever costs are fixed. The presence of variable costs tends to reestablish increasing differences in $a$ and $\beta$ in the profit function, as it does in the free-for-users case, but when costs are not too sensitive to the level of activity, the Claim implies by continuity that the price response may still be decreasing in the tax rate.

\section{A linear example}

Assume, on the users' side, that: $v(x)=v x$ and $\lambda(x)=\lambda x$ for $x \in[0,1]$, and that $F($. is uniform on $[0,1]$. For online sellers, assume that consumers have unit demand, that the transaction price $\bar{p}$ is fixed and exogenous. Users obtain the gross surplus $s \geq \bar{p}$

\footnotetext{
${ }^{14}$ In case an ad valorem tax induces a price decline so powerful that the volume of uploads increases, this tax also implies an increase in social welfare compared to a tax on data collection.
} 
from transacting, and sellers are heterogeneous with respect to their cost $c$, uniformly distributed on $[0, s]$. It follows that $\pi(c)=\bar{p}-c$ and $\bar{c}(a)=\bar{p}-a$; the number of participating sellers is $n^{S}(a) \equiv G(\bar{c}(a))=(\bar{p}-a) / s$ and $\sigma(a)=(s-\bar{p}) n^{S}(a)$.

Since $v($.$) and \lambda($.$) are linear, a participating user \theta$ uploads the maximum amount of data $(x=1)$ if $v-\theta+\lambda \sigma(a) \geq 0$, and no data $(x=0)$ otherwise. A consumer that uploads no data does not obtain any utility, and therefore does not participate. A consumer that uploads the maximum amount of data participates if and only if $v-\theta+\lambda \sigma(a) \geq A$. Therefore, all participating users choose $x(\theta ; a)=1$ and the number of participating users is $n^{U}(A, a) \equiv \bar{\theta}(A, a)=v+\lambda \sigma(a)-A$.

The platform pays a tax $\psi$ on data collection and an ad valorem tax $\beta$ on advertising. Assuming costs are fixed and normalized to 0, the platform's profits are then given by:

$$
\Pi^{P}(A, a ; \psi, \beta)=\frac{n^{U}(A, a)}{1+t}\left[A-\psi+\lambda a(1-\beta) n^{S}(a)\right]
$$

Focusing on an interior solution, the optimal prices ${ }^{15}$ are

$$
\begin{aligned}
a^{*} & =\frac{(2-\beta) \bar{p}-s}{2(1-\beta)} \\
A^{*} & =\frac{1}{2}\left[v+\psi+\frac{\lambda(s-\beta \bar{p})}{4 s(1-\beta)}(3 s-(4-\beta) \bar{p})\right] .
\end{aligned}
$$

This optimum is interior in the neighborhood of $\psi=\beta=0$ if $\bar{p} \geq s / 2$ and $v \in$ $[\lambda(\bar{p}-3 s / 4), 2-\lambda s / 4]$.

It is immediate that $a^{*}$ is independent of $\psi$ but decreases in $\beta$, while $A^{*}$ increases in $\psi$ and also increases in $\beta$ in the neighborhood of $\beta=0$. Note that $n^{S}\left(a^{*}\right)=\frac{(s-\beta \bar{p})}{2 s(1-\beta)}$ increases in $\beta$, while $n^{U}\left(A^{*}, a^{*}\right)=\frac{v}{2}+\frac{\lambda(s-\beta \bar{p})^{2}}{8 s(1-\beta)}-\frac{\psi}{2}$ decreases in $\beta$ at $\beta=0$ : a small ad valorem tax on advertising induces an increase in advertisers' participation but a reduction in users' participation and, therefore, in the volume of data collected.

Computing the variations of fiscal revenues with respect to a tax on data and an $a d$ valorem tax on advertising in the neighborhood of $\psi=\beta=0$, we obtain:

$$
T(\psi, \beta)=\frac{n^{U}\left(A^{*}, a^{*}\right)}{1+t}\left[\psi+\lambda a^{*} \beta n^{S}\left(a^{*}\right)+t\left(A^{*}+\lambda \bar{p} n^{S}\left(a^{*}\right)\right)\right]
$$

\footnotetext{
${ }^{15}$ The Hessian matrix is negative definite in the neighborhood of $\psi=\beta=0$.
} 
and $\partial T / \partial \psi \leq 0$ for $t \geq \bar{t}=1+4 v /(s \lambda)$, as expected from our general results: ${ }^{16}$ a small tax on data collection does not generate additional fiscal revenues for $t$ large enough. Moreover, we obtain: ${ }^{17}$

Claim $5:$ In the example, $\partial T / \partial \beta \geq 0$ for all $t$ if $\bar{p} \leq \frac{8 v+3 \lambda s}{8 v+4 \lambda s}$ s, i.e., a small ad valorem tax on advertising unambiguously increases tax revenues.

A small ad valorem tax on advertising induces the platform to change the balance of its business model. As advertising revenues are taxed compared to subscription revenues, the platform extracts less revenue from sellers, thereby inducing more participation by sellers (higher $n^{S}$ ) and higher benefits for users from targeted advertising (higher $\sigma\left(a^{*}\right)$ ), and it extracts more surplus from users, which is possible as targeted advertising makes users more eager to join the platform. Overall, the platform's profits decrease of course, users participate less (smaller $n^{U}$ ) and so fewer data are collected, which tends to reduce the volume of transactions; but more sellers advertise on the platform, which tends to increase the volume of transactions and users' welfare.

The VAT proceeds consist of the VAT collected on subscriptions (equal to $\frac{t}{1+t} A^{*} n^{U}$ ) and the VAT collected on transactions (equal to $\frac{t}{1+t} \lambda n^{S} n^{U} \bar{p}$ ). The increase in the subscription fee is partially compensated by the increase in benefits from advertising for users so that $A^{*} n^{U}$ actually increases in $\beta$; on the other hand, the number of transactions $\lambda n^{U} n^{S}$ increases for low values of $\bar{p}$ and decreases for high values of $\bar{p},{ }^{18}$ so that overall VAT proceeds always increase when a sizable part of these proceeds comes from VAT on subscriptions, i.e., when $\bar{p}$ is not too large.

Finally, we discuss the impact of a small tax on data collection and a small ad valorem tax on advertising on social welfare. Social welfare is given by $W=C S+S P+T$, that

$$
\begin{aligned}
& { }^{16} \text { More precisely, }\left.\frac{\partial T}{\partial \psi}\right|_{\psi=\beta=0}=\frac{\lambda s+4 v-t \lambda s}{8(1+t)} . \\
& \left.\quad \frac{\partial T}{\partial \beta}\right|_{\psi=\beta=0}=\frac{\lambda(2 \bar{p}-s)(\lambda s+4 v)+\lambda t[s(3 \lambda s+8 v)-4 \bar{p}(\lambda s+2 v)]}{32(1+t)} .
\end{aligned}
$$

As $2 \bar{p}-s \geq 0$ from the assumptions on the interior equilibrium, the term independent of $t$ is positive. Now, the coefficient of $t$ is decreasing in $\bar{p}$, and positive if and only if: $\bar{p}<\frac{8 v+3 \lambda s}{8 v+4 \lambda s} s$.

${ }^{18}$ The variations of the number of transactions w.r.t. $\beta$ are given by:

$$
\left.\frac{\partial\left(n^{U} n^{S}\right)}{\partial \beta}\right|_{\psi=\beta=0}=\frac{1}{16}\left(-3 \lambda \bar{p}+v\left(4-\frac{4 \bar{p}}{s}\right)+2 \lambda s\right),
$$

which is decreasing in $\bar{p}$, positive for low values of $\bar{p}$ and negative for high values of $\bar{p}$ (and negative at the cutoff $\left.\frac{8 v+3 \lambda s}{8 v+4 \lambda s} s\right)$. 
is,

$$
\begin{aligned}
W(\psi, \beta) & =\int_{0}^{n^{U}\left(A^{*}, a^{*}\right)}\left(n^{U}\left(A^{*}, a^{*}\right)-\theta\right) d \theta+\int_{0}^{\bar{c}\left(a^{*}\right)} \lambda n^{U}\left(A^{*}, a^{*}\right)\left(\frac{\pi(c)-a}{1+t}\right) \frac{d c}{s}+T \\
& =\frac{\left(n^{U}\left(A^{*}, a^{*}\right)\right)^{2}}{2}+\lambda s \frac{n^{U}\left(A^{*}, a^{*}\right)\left(n^{S}\left(a^{*}\right)\right)^{2}}{2(1+t)}+T .
\end{aligned}
$$

Since $n^{U}\left(A^{*}, a^{*}\right)$ decreases in $\psi$ and $n^{S}\left(a^{*}\right)$ is independent of $\psi$, it is immediate that a small tax on data collection decreases consumer surplus and sellers' profits. However, if $t<\bar{t}$, this negative impact of the tax can be compensated by its positive impact on fiscal revenues. We find that if the VAT rate is low enough $(t<\tilde{t} \equiv 4 v /(4 v+3 \lambda s)<\bar{t})$, social welfare increases with a small tax on data collection, due the positive impact on fiscal revenues. Otherwise, for higher values of the VAT rate, social welfare decreases. ${ }^{19}$

By contrast, while the effect of a small tax on advertising on consumer surplus is negative, since $n^{U}\left(A^{*}, a^{*}\right)$ decreases in $\beta$, its effect on sellers' profits is a priori ambiguous, as $n^{S}\left(a^{*}\right)$ increases in $\beta$. We find that a small tax on advertising increases welfare if $t<\tilde{t}$, or if $t \geq \tilde{t}$ and $\bar{p}$ is small enough, i.e., $\bar{p} \leq \frac{s}{2}+\frac{s(1+2 t)(4 v+\lambda s)}{24 v t+2 \lambda s(1+5 t)} \equiv \tilde{p} \leq s .^{20}$

To sum up, a small tax on data collection can raise fiscal revenues but only if the VAT rate is small enough. It may however come at the cost of a lower social welfare, unless the VAT rate is very low. By contrast, a small ad valorem tax on advertising raises fiscal revenues irrespective of the VAT rate, and it can also increase social welfare if the surplus that consumers derive from online transactions is large enough.

The fact that social welfare can decrease with the introduction of a tax (on data collection or on advertising) means that the total burden of the tax on consumers and sellers exceeds the fiscal revenues raised. The intuition is that the monopoly platform distorts its prices in response to the tax increase. This is in line with the general analysis of the tax response of a monopolist by Weyl and Fabinger (2013), for example.

However, in our two-sided framework, it is not always true that social welfare decreases

\footnotetext{
${ }^{19}$ We find that
}

$$
\left.\frac{\partial W}{\partial \psi}\right|_{\psi=\beta=0}=\frac{4 v(1-t)-3 \lambda s t}{16(1+t)} .
$$

This expression is negative if $t \geq 1$. If $t<1$, it is positive iff $t<4 v /(4 v+3 \lambda s)$.

${ }^{20}$ We have:

$$
\left.\frac{\partial W}{\partial \beta}\right|_{\psi=\beta=0}=\frac{\lambda s(\lambda s(7 t+2)+4(1+5 t) v)-2 \lambda \bar{p}(\lambda s(1+5 t)+12 v t)}{64(1+t)} .
$$


with the tax. In some cases, it can increase - and this is true both for the tax on data collection and the ad valorem tax on advertising. In contrast to a one-sided environment, the monopoly platforms has two prices, and cares about indirect networks. In some cases, it then has incentives to put less than the full burden of tax on consumers and sellers.

To compare the different tax instruments at hand, we finally compute the marginal costs of public funds for the VAT $(t)$, the tax on data collection $(\psi)$ and the ad valorem tax on advertising $(\beta)$, in the neighborhood of $\psi=\beta=0$. The marginal cost of public funds, $M C_{\tau}$, for a tax instrument $\tau \in\{t, \psi, \beta\}$, is defined as the reduction in welfare following a one dollar increase in tax revenues, ${ }^{21}$ that is,

$$
M C_{\tau}=-\left.\frac{\partial W / \partial \tau}{\partial T / \partial \tau}\right|_{\psi=\beta=0}
$$

For the analysis to be relevant, we assume that the different tax instruments generate additional fiscal revenues, which implies that $t<\bar{t}$ (for $\psi$ ) and $\bar{p} \leq \frac{8 v+3 \lambda s}{8 v+4 \lambda s} s$ (for $\beta$ ). Note that we always have $\partial T / \partial t>0$.

We find that $M C_{t}<M C_{\psi}$, and that $M C_{\psi}$ is increasing in $t$. We also have $M C_{\beta}<$ $M C_{\psi}$ over the relevant range of $\bar{p} .^{22}$ Finally, we find that $M C_{\beta}<M C_{t}$ if $\bar{p}$ is low enough, and $M C_{\beta}>M C_{t}$ otherwise. ${ }^{23}$ In terms of marginal costs of public funds, an $a d$ valorem tax on advertising is therefore the most efficient tax instrument if the surplus that consumers derive from online transactions is large enough. By contrast, a tax on data collection performs poorly compared to the other tax instruments.

\section{Conclusion}

In this paper, we study the impact on fiscal revenues of taxing a two-sided monopolistic platform offering personalized services to users and targeted advertising possibilities to sellers, based on the collection of users' personal data. We show that the introduction of a small tax on data collection fails to increase fiscal revenues if the VAT rate is high enough, due to a tax base interdependence effect between the tax on data and the VAT. Under a supermodularity condition on the platform's profit function, this result generalizes to

\footnotetext{
${ }^{21}$ See, for example, Häckner and Herzing (2016).

${ }^{22} \mathrm{We}$ find that $M C_{\beta}$ is increasing in $\bar{p}$ and that $M C_{\beta}=M C_{\psi}$ for $\bar{p}=s$. Therefore, since we have assumed that $\bar{p} \leq \frac{8 v+3 \lambda s}{8 v+4 \lambda s} s$, we have $M C_{\beta}<M C_{\psi}$ over the relevant range of $\bar{p}$.

${ }^{23}$ We have $M C_{\beta}<M C_{t}$ for $\bar{p}=s / 2, M C_{\beta}>M C_{t}$ for $\bar{p}=\frac{8 v+3 \lambda s}{8 v+4 \lambda s} s$, and $M C_{\beta}$ increasing in $\bar{p}$.
} 
any per unit tax. However, an ad valorem tax on subscriptions or on advertising can raise fiscal revenues, irrespective of the VAT rate.

These results clearly suggest that creating a specific tax on data is probably a poor way for governments to capture a bigger share of the digital value creation. Given that most of the business models involved in the digital economy rely on advertising based on collected data, an ad valorem tax on targeted advertising seems to be a preferable policy.

We have analyzed the impact of taxation on a monopolistic platform. A natural extension would be to introduce platform competition within our framework. For example, an interesting question would be to study the effect of taxation on the market structure of the two-sided market. Another natural extension would be to endogenize the technology developed by the platform to take advantage of the data it collects and analyze how a tax on data would affect its investment decision on such a technology. 


\section{References}

Anderson, S. and S. Coate (2005): "Market Provision of Broadcasting: a Welfare Analysis", Review of Economic Studies, 72(4), 947-972.

Arora, N., Ghose, A., Hess, J. D., Iyengar, R., Jing, B., Joshi, Y., Kumar, V., Lurie, N.,

Neslin, S., Sajeesh, S., Su, M., Syam, N., Thomas, J. and Z. J. Zhang (2008): "Putting one-to-one marketing to work: Personalization, customization, and choice", Marketing Letters, 19, 305-321.

Armstrong, M. (2006): "Competition in Two-sided Markets", RAND Journal of Economics, 34, 309-328.

Bloch, F. and G. Demange (2016): "Taxation and Privacy Protection on Internet Platforms", Working paper.

Caillaud, B. and B. Jullien (2003): "Chicken and Egg: Competition among Intermediation Service Providers", RAND Journal of Economics, 37, 668-691.

Colin, N. and P. Collin (2013): Mission d'expertise sur la fiscalité de l'économie numérique.

Conseil National du Numérique (2013): Concertation sur la fiscalité du numérique, Report 2013-03.

Delipalla, S. and M. Keen (1992): "The Comparison between Ad Valorem and Specific Taxation under Imperfect Competition", Journal of Public Economics, 49, 351-357.

Gaspar, V., Collin, P., Devereux, M.P., Snabe, J.H., Varrak, T., Walsh, M., and B. Westberg (2014): Commission Expert Group on Taxation of the Digital Economy Report.

Häckner, J. and M. Herzing (2016): "Welfare effects of taxation in oligopolistic markets", Journal of Economic Theory, 163, 141-166.

HM Treasury (2014): "Finance Bill 2015: Diverted Profits Tax", HM Revenue and Custom.

Kind, H.J., Koethenbuerger, M. and G. Schjelderup (2008): "Efficiency Enhancing Taxation in Two-sided Markets", Journal of Public Economics, 92(5-6), 1531-1539. 
Kind, H.J., Koethenbuerger, M. and G. Schjelderup (2010a): “Tax Responses in Platform Industries", Oxford Economic Papers, 62(4), 764-783.

Kind, H.J., Koethenbuerger, M. and G. Schjelderup (2010b): "On Revenue and Welfare Dominance of Ad Valorem Taxes in Two-sided Markets", Economics Letters, ,104(2), $86-88$.

OECD (2014): "Report on the Tax Challenges of the Digital Economy", Center for Tax Policy and Administration, Committee on Fiscal Affairs.

Peitz, M. and T. Valletti (2008): "Content and Advertising in the Media: Pay-TV versus Free-to-air", International Journal of Industrial Organization, 26(4), 949-965.

Rochet, J.C. and J. Tirole (2003): "Platform Competition in Two-sided Markets", Journal of the European Economic Association, 1, 990-1029.

Singer, N. (2015): "Sharing Data, but Not Happily", The New York Times.

Suits, D.B. and R.A. Musgrave (1953): "Ad Valorem and Unit Taxes Compared", Quarterly Journal of Economics, 67, 598-604.

Weyl, E.G. and M. Fabinger (2013): "Pass-Through as an Economic Tool: Principles of Incidence under Imperfect Competition", Journal of Political Economy, 121, 528-583. 